\title{
Azasugar-Containing Phosphorothioate Oligonucleotide (AZPSON) DBM-2198 Inhibits Human Immunodeficiency Virus Type 1 (HIV-1) Replication by Blocking HIV-1 gp120 without Affecting the V3 Region
}

\author{
Jinjoo Lee, Se Eun Byeon, Ju Yeol Jung, Myeong-Ho Kang, Yu-Jin Park, Kyeong-Eun Jung ${ }^{1}$, and \\ Yong-Soo Bae*
}

\begin{abstract}
DBM-2198, a six-membered azasugar nucleotide (6-AZN)containing phosphorothioate $(P=S)$ oligonucleotide (AZPSON), was described in our previous publication [Lee et al. (2005)] with regard to its antiviral activity against a broad spectrum of HIV-1 variants. This report describes the mechanisms underlying the anti-HIV-1 properties of DBM-2198. The LTR-mediated reporter assay indicated that the anti-HIV-1 activity of DBM-2198 is attributed to an extracellular mode of action rather than intracellular sequence-specific antisense activity. Nevertheless, the antiviral properties of DBM-2198 and other AZPSONs were highly restricted to HIV-1. Unlike other $P=S$ oligonucleotides, DBM-2198 caused no host cell activation upon administration to cultures. HIV-1 that was pre-incubated with DBM-2198 did not show any infectivity towards host cells whereas host cells pre-incubated with DBM-2198 remained susceptible to HIV-1 infection, suggesting that DBM-2198 acts on the virus particle rather than cell surface molecules in the inhibition of HIV-1 infection. Competition assays for binding to HIV-1 envelope protein with anti-gp120 and anti-V3 antibodies revealed that DBM-2198 acts on the viral attachment site of HIV-1 gp120, but not on the V3 region. This report provides a better understanding of the antiviral mechanism of DBM-2198 and may contribute to the development of a potential therapeutic drug against a broad spectrum of HIV-1 variants.
\end{abstract}

\section{INTRODUCTION}

Phosphorothioate oligonucleotides ( $\mathrm{P}=\mathrm{S} \mathrm{ONs}$ ) or phosphoro-

Department of Biological Science, Sungkyunkwan University, Suwon 446-740, Korea, ${ }^{1}$ ST PHARM 231, Siheung 429-848, Korea

${ }^{*}$ Correspondence: ysbae04@skku.edu

Received 15 May, 2014; revised 29 October, 2014; accepted 3 November, 2014; published online 27 January, 2015

Keywords: anti-HIV-1 mechanism, DBM-2198, gp120, six-membered azasugar nucleotide $(6-\mathrm{AZN})$-containing phosphorothioate $(\mathrm{P}=\mathrm{S})$ oligonucleotide (AZPSON), V3 thioated substrate have been demonstrated to have antiviral activities by blocking viral entry (Luganini et al., 2008; Matsumura et al., 2009), replication (Torrence et al., 2006), packaging (Giannecchini et al., 2009; Takahashi et al., 2009), translation (Gonzalez-Carmona et al., 2013), and in some cases by targeting microRNA (Gebert et al., 2014; Lanford et al., 2010). Among $\mathrm{P}=\mathrm{S}$ ONs studied as antiviral compounds, $\mathrm{P}=\mathrm{S}$ ONs that inhibit HIV-1 infection have attracted attention. Most studies on antisense oligonucleotide (AS-ON) against human immunodeficiency virus (HIV-1) have been conducted using $\mathrm{P}=\mathrm{S}$ ONs. However, $\mathrm{P}=\mathrm{S}$ ONs have not been shown to be able to penetrate the cytoplasm up to the effective concentration without additional procedures such as artificial transfection in any of the cell types examined. Nevertheless, non-specific reactions enhance the anti-HIV-1 activity of the $\mathrm{P}=\mathrm{S}$ ONs.

A variety of possible mechanisms of action have been proposed to account for the non-sequence-specific ability of the $P$ = S ONs to inhibit HIV-1 replication. These suggested mechanisms include blocking of viral adsorption (Luganini et al., 2008; Wyatt et al., 1994) and/or inhibition of HIV-1-specific enzymes, such as reverse transcriptase (Marshall and Caruthers, 1993; Marshall et al., 1992) or integrase (Jing and Hogan, 1998; Jing et al., 2000). $\mathrm{P}=\mathrm{S}$ oligodeoxycytidine [poly $(\mathrm{SdC})_{28}$ ] interacts specifically with the positively-charged V3 loop of HIV-1 gp120 (Vaillant et al., 2006), possibly resulting in the inhibition of HIV-1 replication. It was also reported that T2G4T2 (5'-TTGGGGTT3'; ISIS-5320), a $P=S$ ON identified as an HIV-1 inhibitor, forms a tetrameric G-quartet structure and binds to the cationic V3 loop region of the gp120 viral envelope glycoprotein (Wyatt et al., 1994), as does poly(SdC $)_{28}$. In both cases, the tetrameric G-quartet structure and the sulfur-containing backbone are believed to be involved in binding to V3, followed by the inhibition of virus-to-cell and cell-to-cell infections. Another study showed that $\mathrm{P}=\mathrm{S}$ ONs interact with a peptide derived from the $\mathrm{N}$-terminal heptad repeat region of gp41, blocking gp41 sixhelix bundle formation (Vaillant et al., 2006). Recently, a short 14-mer $P=S 2^{\prime}$ deoxyribose backbone was demonstrated to enhance anti-HIV-1 activity by blocking Toll-like receptor 7 (TLR7) and TLR9, thus inhibiting the initial spread of HIV-1 after infection (Fraietta et al., 2010).

In our previous report (Lee et al., 2005), we demonstrated that 
Table 1. Sequence composition and anti-HIV-1 activity of each oligonucleotide

\begin{tabular}{|c|c|c|c|c|}
\hline DBM-ON & Sequence composition $^{a}$ & Backbone $^{b}$ & Targeting site $^{c}$ & $\mathrm{EC50}(\mu \mathrm{M})^{\mathrm{d}}$ \\
\hline DBM-2134 & A GC TCC CAG GCT CAG ATC & $P=S$ & HIV-1 TAR & $0.13 \pm 0.02$ \\
\hline DBM-2136 & AGC TCC CAG GCT CAG ATC & $P=S$ & HIV-1 TAR & Nle \\
\hline DBM 2172 & ATC TGC TCA GAG ATA CAA & $P=S$ & SIV TAR-1 & $0.22 \pm 0.07$ \\
\hline DBM-2173 & A GT CAC TCA GGA CTC TGG & $P=S$ & SIV TAR-2 & $0.25 \pm 0.12$ \\
\hline DBM-2174 & АСТ CAT CA G СТ AAG CTA & $P=S$ & Polio IRES & $0.18 \pm 0.05$ \\
\hline DBM-2177 & АTT GAG GCT TAA GCA GTG & $P=S$ & HIV-1 LTR & $0.16 \pm 0.04$ \\
\hline DBM-2180 & AGC TCC CAG GCT CAG ATC & $P=O$ & HIV-1 TAR & $>2.0$ \\
\hline DBM-2193 & A GC TCC CA G GCT CA A ATC & $P=S$ & HIV-1 TAR & $0.14 \pm 0.03$ \\
\hline DBM-2198 & АС Ст САС тСА СтC АСт САС & $P=S$ & Random & $0.08 \pm 0.02$ \\
\hline DBM-2240 & A CG CAC GCA CTC ACG CAC & $P=S$ & CpG Random & $0.12 \pm 0.02$ \\
\hline
\end{tabular}

$\sqrt{A}$ represents the 6-membered azasugar-containing deoxyadenosine nucleotide.

${ }^{\mathrm{b}}$ Oligonucleotide linkage backbone: $\mathrm{P}=\mathrm{S}$ (phosphorothioate), $\mathrm{P}=\mathrm{O}$ (phosphodiester)

"Target site is the region complementary to each oligonucleotide. "Random" indicates no specific target site.

${ }^{\mathrm{d}}$ EC50 value of each DBM-ON was calculated by the MTT assay with MT-4 cells and HIV-1IIIB strain, as described in "Materials and Methods". Each value represents the mean \pm S.D. of triplicates. $P<0.01$.

${ }^{\mathrm{e}} \mathrm{NI}$, no inhibition

the newly designed six-membered azasugar nucleotide (6AZN)-containing $\mathrm{P}=\mathrm{S}$ ONs (AZPSONs) have much more potent anti-HIV-1 activity than previously reported $P=S$ ONs without concomitant cytotoxicity. Among the AZPSONs tested, DBM-2198, which contains five 6-AZNs in its random sequence, exhibited the most prominent anti-HIV-1 activity. DBM-2198 functions against a broad spectrum of HIV-1 variants, including T cell-tropic, monotropic, and drug-resistant HIV-1 variants. In the present study, we characterized the detailed mechanisms underlying the anti-HIV-1 activities of DBM-2198 and its HIV-1 specificity. We found that (i) DBM-2198 and other AZPSONs specifically inhibit HIV-1, (ii) DBM-2198 treatment does not cause any host cell activation or damage, (iii) DBM-2198 acts on HIV-1 gp120, resulting in the inhibition of viral attachment, and (iv) in contrast to other polyanionic $\mathrm{P}=\mathrm{S}$ ONs, DBM-2198mediated blocking of HIV-1 replication is unlikely to be associated with the V3 region of gp120.

\section{MATERIALS AND METHODS}

\section{Synthesis of AZPSONs and other ONs}

The synthesis of modified adenine nucleoside (6-AZN) containing a 6-AZS has been described previously (Jung et al., 1999). AZPSONs, including DBM-2198, and control P = S ON (DBM2136) were synthesized as described previously (Lee et al., 2005). The sequence composition and target site of each AZPSON and $\mathrm{P}=\mathrm{S}$ ON are summarized in Table 1.

\section{Cells and viruses}

Jurkat-tat (Tat-expressing Jurkat cells) cells were obtained from J. Sodroski (Dana-Farber Cancer Institute, Harvard Medical School). C8166, CEMX-174, HeLa-CD4-LTR- $\beta$-gal (Magi), U373CD4-CXCR4-Magi, and U373-CD4-CCR5-Magi cells were obtained from the AIDS Research and Reference Reagent Program (ARRRP, NIH, USA). Jurkat E6 (TIB152), and HeLa cells (CCL2) were purchased from the American Type Culture Collection (ATCC). HIV-1 $1_{\text {IIIB }}, \mathrm{HIV}-1_{\mathrm{CC}}, \mathrm{HIV}-1_{\mathrm{Ba}-\mathrm{L}}$, and $\mathrm{SIV}_{\mathrm{mac}} 239$ were obtained from the ARRRP. Poliovirus Sabin 1 cDNA was kindly provided by A. Nomoto (Tokyo University, Japan). In general, cells were grown and maintained in RPMl 1640 (Life Technologies, Inc., USA) supplemented with $10 \%$ heat-inactivated
FCS (Life Technologies, Inc.), penicillin (250 units $/ \mathrm{ml}$ ), and streptomycin $(250 \mu \mathrm{g} / \mathrm{ml})$. Opti-MEM (Life Technologies, Inc.) was also used to assess the effects of serum on the antiviral activity of the AZPSONs.

\section{Antiviral activity assay}

Susceptible cells were infected with HIV-1, simian immunodeficiency virus (SIV), or poliovirus at an appropriate multiplicity of infection (MOI) for $1 \mathrm{~h}$ at $37^{\circ} \mathrm{C}$ and then washed and cultured in the presence of either AZPSONs or $\mathrm{P}=\mathrm{S}$ ONs at several different concentrations. The anti-HIV-1 activity of each AZPSON was assessed according to the inhibition of HIV-1 replication, which was measured by the number of syncytia, and/or reverse transcriptase (RT) activity, or by a visual infection assay as described previously (Lee et al., 2005). The anti-HIV-1 activity of each DBM-ON was also expressed by $\mathrm{EC}_{50}$ values, which were calculated 4 days post-infection (p.i.) by a tetrazoliumbased MTT [3-(4,5-dimethylthiazol-2-yl)-2,5-diphenyltetrazolium] (Sigma Chemical Co.) assay as described previously (Lee et al., 2005). Antiviral activities of these ONs against SIV or poliovirus were assessed according to the inhibition of RT activity or the inhibition of plaque forming units (pfu), respectively.

Visual infection assay for titration of infectious virions A visual infection assay was performed with U373-CD4-CXCR4Magi or U373-CD4-CCR5-Magi cells as described previously (Vodicka et al., 1997) with minor modifications (Lee et al., 2005). In brief, cells in monolayers were infected for $1 \mathrm{~h}$ with serially diluted HIV-1 solutions, washed twice with PBS, and then cultured in Dulbecco's Modified Eagle's Medium (DMEM, Life Technologies, Inc.) supplemented with 10\% FBS. Two days after infection, the cells were washed and fixed with $1 \%$ formaldehyde and $0.2 \%$ glutalaldehyde solution, followed by staining with $0.04 \%$ 5-bromo-4-chloro-3-indoryl- $\beta$-D-galactopyranoside (X-gal; Molecular Probes) for $2 \mathrm{~h}$ at $37^{\circ} \mathrm{C}$. Blue cells were counted under an inverted microscope and expressed as the titer of infectious virus particles in each sample.

\section{Transfection and CAT assay}

pU3III-CAT plasmid containing the HIV-1 long terminal repeat (LTR)-chloramphenicol acetyltransferase (CAT) reporter con- 


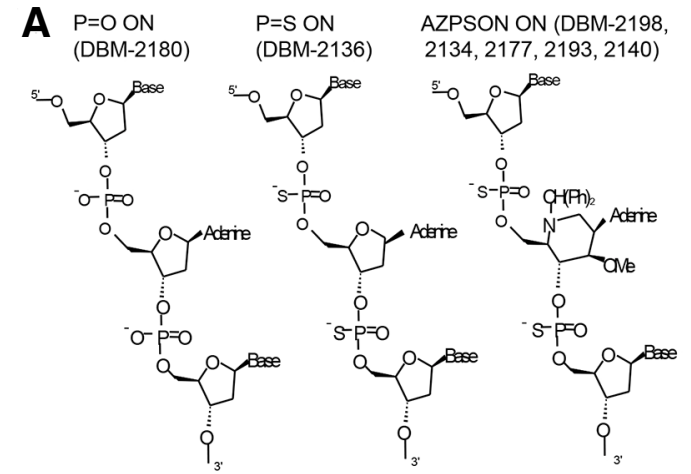

B

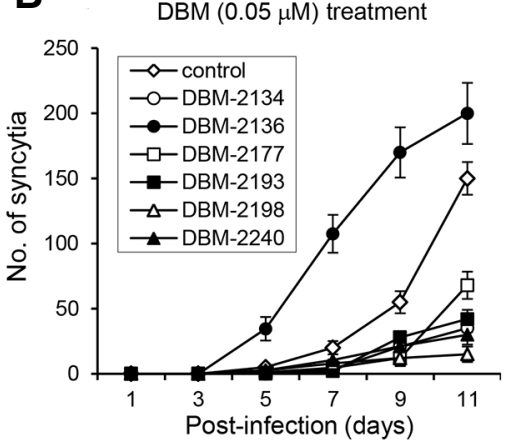

C

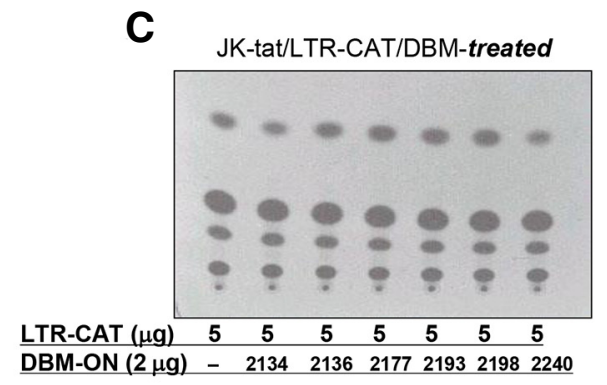

E

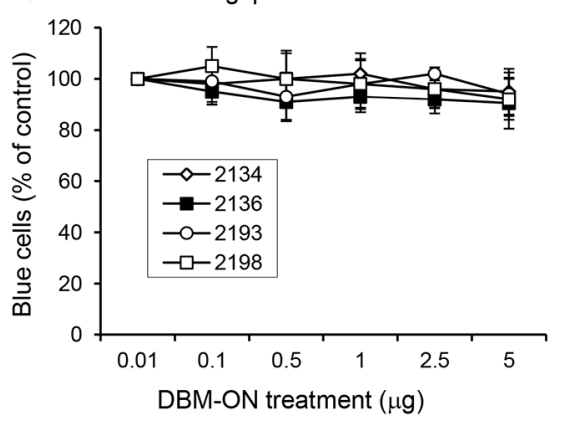

D

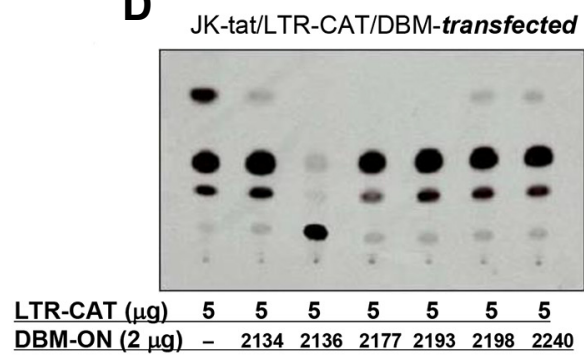

Fig. 1. Inhibitory effects of AZPSONs on HIV-1 replication and LTR-mediated reporter expression. (A) Chemical structure of AZPSONs. (B) Inhibitory effects of AZPSONs on HIV-1 replication by simple treatment of virusinfected cell cultures. Jurkat-tat cells were infected with HIV-1 ( $\mathrm{HXBc2} / \Delta$ tat) at a $0.001 \mathrm{MOI}$, and then cultured in 96-well plates in Opti-MEM for 11 days in the presence of DBM-ONs at a final concentration of $0.05 \mu \mathrm{M}$. Syncytia were counted under an inverted microscope. (C) Jurkat-tat cells were transfected with the LTR-CAT plasmid and then cultured in the presence of $2 \mu \mathrm{g}$ of DBM-ONs $(0.36 \mu \mathrm{M})$. (D) Jurkattat cells were co-transfected with LTR-CAT plasmid and DBMONs, and then cultured in the absence of DBM-ONs (lower panel). Two days after transfection, the cells were harvested and CAT activity was measured. (E, F) Magi (HeLa-CD4-LTR- $\beta$-gal) cells $\left(1 \times 10^{6}\right)$ were transfected with $2 \mu \mathrm{g}$ of pSV2-tat plasmid and then treated $(E)$ or co-transfected (F) with different amounts of DBM-ONs. After 2 days the cells were fixed and stained with $\mathrm{X}$-gal. The blue cells were counted under an inverted microscope and the number of blue cells on each plate was expressed as a percentage based on the number of blue cells on the control plate of cells transfected with the pSV2-tat plasmid alone. struct was obtained from the AIDS Research and Reference Reagent Program (NIH, USA). In each experiment, $2 \times 10^{6}$ Jurkat-tat cells were transfected with $2 \mu \mathrm{g}$ of pU3III-CAT, either with or without AZPSONs, using a GenePorter ${ }^{\mathrm{TM}}$ transfectant kit (Gene Therapy System Inc., USA) according to the manufacturer's instructions. Two days after transfection the cells were washed twice with cold PBS and then resuspended in 1 $\mathrm{ml}$ of TNE buffer (40 mM tris- $\mathrm{HCl}, \mathrm{pH} 7.5,1 \mathrm{mM}$ EDTA, 150 $\mathrm{mM} \mathrm{NaCl})$. The cells were disrupted by three cycles of freezing and thawing, and then incubated for $10 \mathrm{~min}$ at $60^{\circ} \mathrm{C}$ to inactivate cell-originated CAT activity. The CAT activity of each transfectant was determined as described previously (VelazquezCampoy et al., 2001).

\section{Internalization and sequence-specific inhibition assay}

Magi (HeLa-CD4- $\beta$-gal) cells (Kimpton and Emerman, 1992) were transfected with $2 \mu \mathrm{g}$ of pSV2-tat plasmid (kindly provided by J. Sodroski, DFCl, Harvard Medical School), and then cultured in DMEM containing DBM-ONs. Magi cells were also cotransfected with $2 \mu \mathrm{g}$ of pSV2-tat plasmid and increasing amounts of DBM-ONs. Two days after transfection the cells were fixed and stained as described above in the section on HIV-1 titration by visual infection assay. The blue cells were counted under an inverted microscope and the inhibition capacity was expressed according to the decreasing proportion of blue cells.

Detection of intracellular $\mathrm{Ca}^{2+}$ changes in DBM-ON-treated cells

The transient increase in intracellular $\mathrm{Ca}^{2+}$ intensity was measured as described previously (Asoh et al., 2002). Cells arrested in the $\mathrm{G} 1$ stage by $2 \mathrm{~h}$ of incubation on ice or by culturing in serum-free media were incubated for $60 \mathrm{~min}$ at RT in medium containing the fluorescent $\mathrm{Ca}^{2+}$ indicator Fura-4 (Molecular Probes) at a final concentration of $3 \mu \mathrm{M}$. Cells $\left(2 \times 10^{6}\right.$ cells $\left./ \mathrm{ml}\right)$ were washed once with HBSS and placed on poly L-Lysinecoated cover slides for $15 \mathrm{~min}$. The attached cells were treated with DBM-ONs and changes in intracellular $\mathrm{Ca}^{2+}$ intensity were measured by acquisition of fluorescent images every $10 \mathrm{~s}$ using a confocal scanning microscope (Karl Zeiss). 

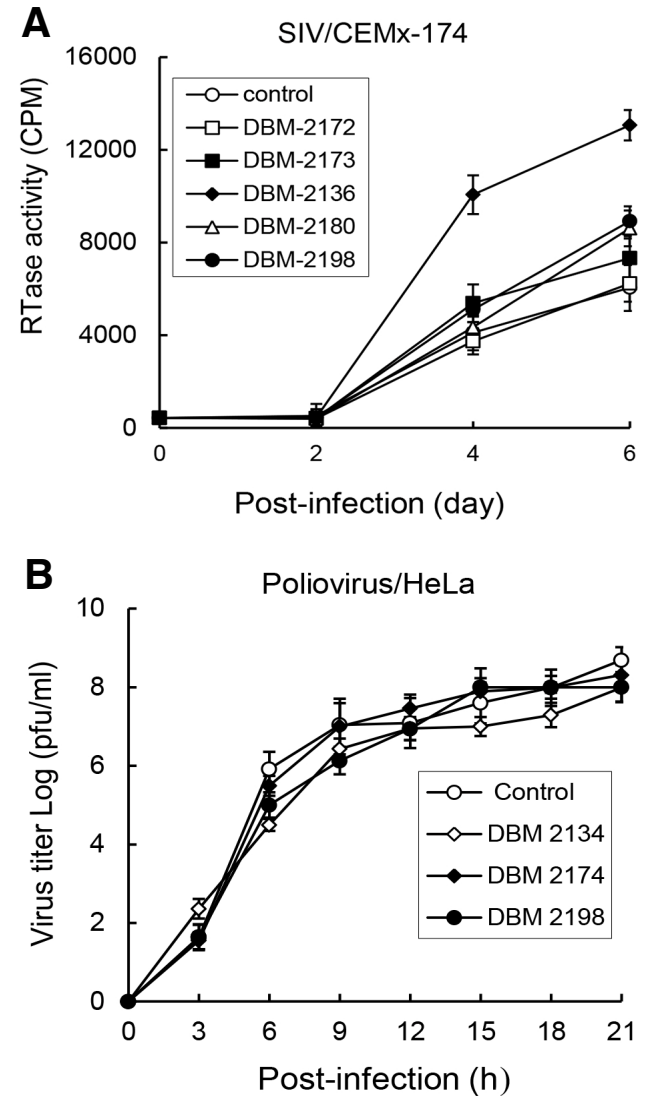

Fig. 2. Effects of AZPSONs on the replication of SIV and poliovirus. (A) CEMx174 cells were infected with SIV $_{\text {mac }} 239$ at $0.01 \mathrm{MOI}$ for $1 \mathrm{~h}$. Cells were washed twice and then cultured in the presence of DBMONs at a final concentration of $0.5 \mu \mathrm{M}$. Culture supernatants were harvested every 2 days and the amount of SIV was measured by RT assay as previously described (Lee et al., 2005). (B) Subconfluent monolayer HeLa cells were infected with the Sabin 1 poliovirus at $0.1 \mathrm{MOI}$ for $1 \mathrm{~h}$. Cells were washed twice, and then refed with Opti-MEM containing DBM oligonucleotide at a final concentration of $0.5 \mu \mathrm{M}$. Culture supernatants were harvested every 3 $\mathrm{h}$ and titrated by plaque forming unit (pfu).

\section{Flow cytometry}

COS-1 cells transfected with pcDNA3 control vector (Invitrogen) or pCDNA-gp160 recombinant plasmid (mutation at gp120-gp41 processing site of HIV-1 $1_{\text {IIIB }}$ env gene, kindly provided by JS Park, Hallym University, Korea), were used in a FACS competition assay. HIV-1 $1_{\text {IIIB }}$ gp160-expressing COS-1 cells were pre-treated with rabbit anti-gp120 antisera (generated in our laboratory) or anti-V3 antisera (provided by ARRRP), and then further incubated with $0.5 \mu \mathrm{M}$ FITC-labeled DBM2198 for $1 \mathrm{~h}$. After washing, FITC-labeled cells were assessed using a FACSCalibur flow cytometer (Becton Dickinson), as described previously (Miah et al., 2013).

\section{Western blot analysis}

Western blot analysis was performed as described previously (Khan et al., 2013; Yoon et al., 2009). In brief, HIV-1 IIIB $_{\text {gp160- }}$ transfected COS-1 cells were lysed, subjected to 8-12\% SDSPAGE, and then transferred to a PVDF membrane (Millipore).
A

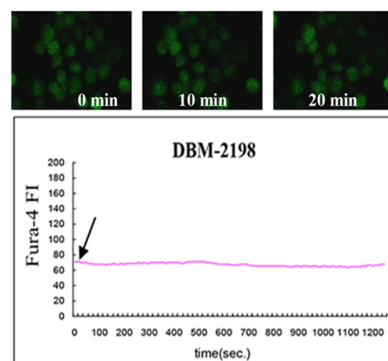

B

HIV-1 RTMDRI $/ \mathrm{C} 8166$

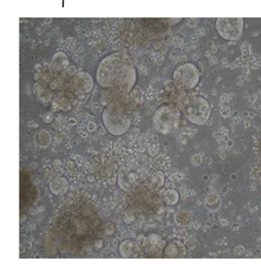

control

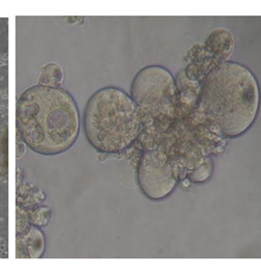

+ DBM-2136

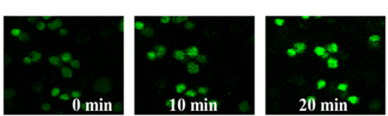

DBM-2136

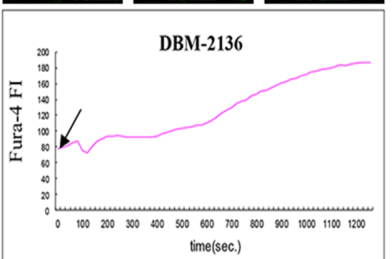

Fig. 3. Effects of DBM-2198 on host cell activation. (A) C8166 cells arrested in $\mathrm{G} 1$ by incubation on ice for $2 \mathrm{~h}$ were treated with $3 \mu \mathrm{M}$ Fura-4 for $60 \mathrm{~min}$ at RT. A $20-\mu \mathrm{l}$ sample of cells $\left(2.0 \times 10^{6} \mathrm{cells} / \mathrm{ml}\right)$ was placed on Poly L-Lysine-coated cover slides and incubated for $15 \mathrm{~min}$. The attached cells were treated with $0.5 \mu \mathrm{M}$ DBM-ONs (2136 and 2198) and intracellular $\mathrm{Ca}^{2+}$ intensity was measured every $10 \mathrm{~s}$ by confocal microscopy. The average $\mathrm{Ca}^{2+}$ intensity of 100 cells was plotted as a function of time. Confocal images are also shown for selected time points. (B) C8166 cells were infected with HIV-1 $1_{\text {RTMDRI }}$ (AZT-, ddC-, ddl-, and nevirapine-resistant virus) for $1 \mathrm{~h}$. Cells were washed and cultured in the presence of DBM2136 and 2198 at a final concentration of $0.5 \mu \mathrm{M}$. Cells were photographed 4 days p.i. at a magnification of $100 \mathrm{X}$.

Membranes were incubated with anti-gp120 rabbit sera at $4^{\circ} \mathrm{C}$ overnight, and then further incubated with HRP-conjugated goat anti-rabbit secondary antibodies. Western blot bands were assessed with a chemiluminescent imaging system (Davinci Chemi ${ }^{\mathrm{TM}}$ ).

Statistical analysis

Most of the statistical data were collected in triplicate, and the results are expressed as the geometric mean \pm standard deviation (S.D.). Statistical significance was evaluated using a Student's $t$-test. Data with a $P$ value $\leq 0.05$ were considered to be significant.

\section{RESULTS}

AZPSONs act extracellularly rather than in an intracellular sequence-specific manner

AZPSONs are newly designed six-membered azasugar nucleotide (6-AZN)-containing $\mathrm{P}=\mathrm{S}$ ONs (Fig. $1 \mathrm{~A})$. The sequences and target genes of AZPSONs used in this study are summarized in Table 1. As described in our previous report (Lee et al., 2005), most of the AZPSONs showed strong anti-HIV-1 activity by simple administration into HIV-1-infected cultures (Fig. 1B). The $\mathrm{EC}_{50}$ values of the selected AZPSONs were much lower than those of $\mathrm{P}=\mathrm{S}$ ON (DBM-2136) or $\mathrm{P}=\mathrm{O}$ ON (DBM-2180), and DBM-2198 was the most active of the AZPSONs with regard to 


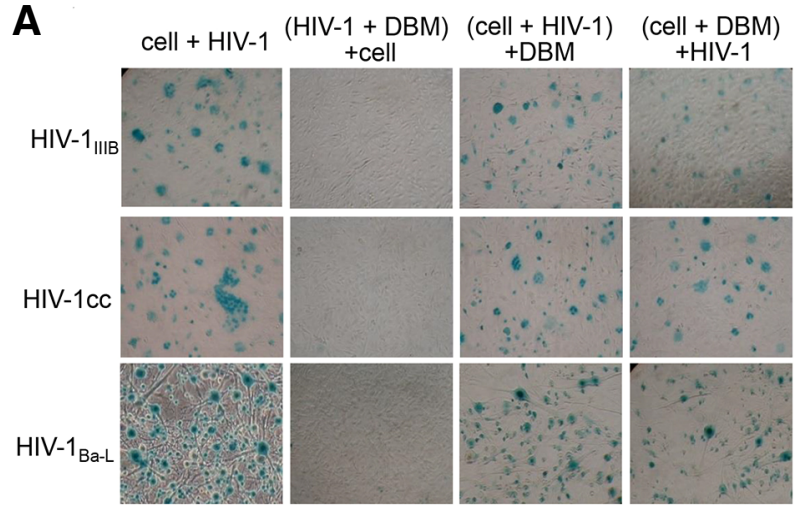

B

HIV-1/U373-Magi(CD4-CXCR4/CCR5)

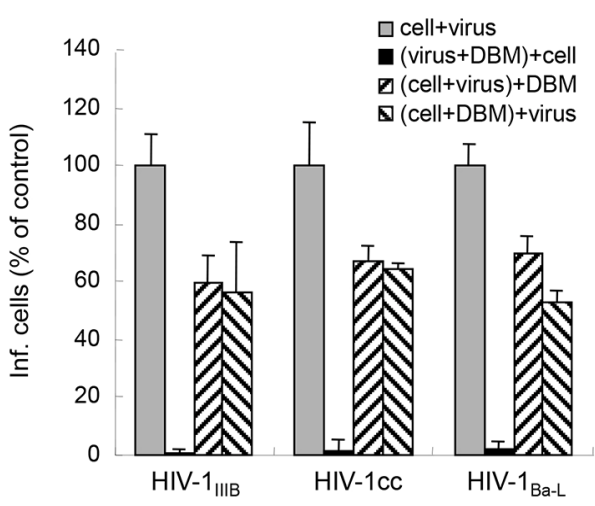

Fig. 4. Mode of antiviral action of DBM-2198. Monolayer cultures of U373-CD4-CXCR4-Magi cells and U373-CD4-CCR5-Magi cells were infected for $1 \mathrm{~h}$ with $0.05 \mathrm{MOI}$ of HIV-1 $1_{\text {IIIB }}$ HIV-1cc, or HIV-1 $1_{\text {Ba-L }}$ using three different infection protocols as described in the text and summarized in the legend. Cells were washed twice and cultured in the presence of $0.5 \mu \mathrm{M}$ DBM-2198. Two days after infection the cells were fixed and stained with X-gal solution. (A) Cells were photographed at a magnification of $40 \mathrm{X}$. Blue spots represent the HIV-1-infected cells. (B) Blue spots were counted in triplicate, and antiviral activities were expressed as a percentage of the untreated positive control. The data are represented as mean \pm S.D of three independent experiments.

its $\mathrm{EC}_{50}$ (Table 1). To determine whether AZPSONs function intracellularly without any extra transfection procedure we cultured pU3III (LTR)-CAT-transfected Jurkat-tat cells in the presence of AZPSON for 2 days and then assessed the CAT activity of each sample. None of the tested AZPSONs (DBM-2134, $2177,2193,2198$, and 2240) or P = S ON (DBM-2136) exhibited any discernable suppression of intracellular LTR/tatmediated CAT reporter expression when administered in the culture media (Fig. 1C). On the other hand, when Jurkat-tat cells were co-transfected with these ONs together with the pU3III (LTR)-CAT reporter gene, DBM-2136 ( $P=S$, no AZN) exhibited a marked suppression of LTR/tat-mediated CAT expression. In contrast, the AZPSONs (AZN-containing $\mathrm{P}=\mathrm{S}$; DBM-2134, 2177, 2193, 2198, and 2140) did not show any clear suppression of CAT activity even though DBM-2134 and 2193 have the same target sequence as DBM-2136 (Fig. 1D). The same results were obtained in experiments with pSV2-tattransfected HeLa-CD4-Magi (LTR- $\beta$-gal) cells. No reductions in the number of blue cells were observed by simple treatment of the culture with DBM-2134, 2136, 2193, or 2198 (Fig. 1E). However, when HeLa-CD4-Magi cells were co-transfected with these ONs and pSV2-tat plasmid only DBM-2136 reduced the number of blue cells in a dose-dependent manner; none of the tested AZPSONs (DBM-2134, 2193, and 2198) induced any reduction in the number of blue cells (Fig. 1F) consistent with data from the CAT assay. These results suggest that (i) not only AZPSONs, but also other $\mathrm{P}=\mathrm{S}$ ONs, were unable to enter the cytoplasm through the plasma membrane by simple treatment of infected cells, and (ii) the AZPSONs were not functional in the cytoplasm even after transfection. Taken together, it may be concluded that the anti-HIV-1 activity of AZPSONs by simple treatment of HIV-1-infected cultures is attributable to extracellular mechanisms, rather than intracellular sequencespecific inhibition.

\section{AZPSONs do not inhibit replication of other viruses}

If AZPSONs operate extracellularly, they may also interfere with other viruses. To determine whether AZPSONs affect other viral replications, the replication of SIV and poliovirus was assessed at an $\mathrm{MOI}$ of 0.01 and 0.1 , respectively, in the presence of AZPSONs or DBM-2136 in CEMx-174 and HeLa cells. Neither AZPSONs (2172 and 2173, anti-SIV TAR; 2174, antiIRES of poliovirus; 2198 , random sequence) nor $P=S$ ONs (2136, anti-TAR) inhibited the replication of SIV (Fig. 2A) or poliovirus (Fig. 2B) to any appreciable degree, compared with the untreated controls (Fig. 2). The same results were obtained in experiments with cells that were pre-treated with AZPSONs, or with these viruses that were pre-incubated with AZPSONs (data not shown). In the case of DBM-2136 treatment, SIV replication was significantly enhanced, rather than inhibited (discussed further in the following section). These results imply that the extracellular antiviral activity of AZPSONs is probably HIV-1-specific and does not affect other viral receptors, or at least those associated with infection of SIV or poliovirus.

DBM-2198, a typical AZPSON, does not cause host cell activation

Even though AZPSONs were exclusively effective in inhibiting HIV-1 replication, they cannot be developed as anti-HIV-1 drugs if they cause host cell activation by interacting with cell surface molecules. Activated T cells are more susceptible to HIV-1 infection than naive or quiescent T cells (Koning et al., 2005; Zack et al., 2013). When T cells are activated, the intracellular $\mathrm{Ca}^{2+}$ concentration is increased and sustained by $\mathrm{Ca}^{2+}$ influx through the plasma membrane (Feske, 2013; Wulfing et al., 1998). We therefore examined the $\mathrm{Ca}^{2+}$ influx as an indicator of T-cell activation. Cells were examined for a transient increase in intracellular free $\mathrm{Ca}^{2+}$ every $10 \mathrm{~s}$ starting immediately after treatment with DBM-ONs as described previously (Asoh et al., 2002). As shown in Fig. 3A, intracellular $\mathrm{Ca}^{2+}$ intensity did not change over a 20-min period in the DBM-2198-treated cells whereas it continuously increased in the DBM-2136-treated cells. These results strongly suggest that treatment with DBM2198 does not cause any host cell activation, but DBM-2136 does. In fact, HIV-1 ${ }_{\text {IIIB }}$-infected cultures treated with DBM-2136 exhibited substantial syncytium formation compared with the untreated control, whereas DBM-2198 treatment completely inhibited syncytium formation in the HIV-1-infected culture (Fig. $3 \mathrm{~B})$. These results provide a clear explanation for the observation that DBM-2136-treated cells were more susceptible to HIV1 and SIV (Fig. 2A) than the untreated control. 
A

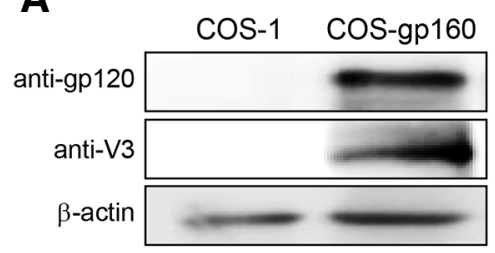

B

COS-gp160/a-gp120/FITC-DBM-2198

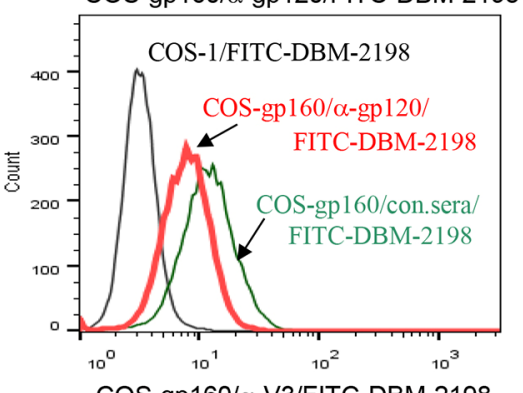

COS-gp $160 / \alpha-V 3 / F I T C-D B M-2198$

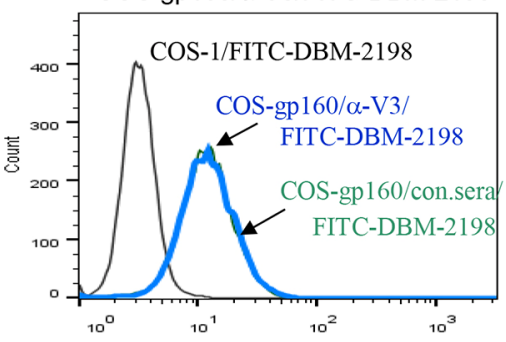

DBM-2198 acts on the HIV-1 attachment site

DBM-2198 inhibited replication of $\mathrm{SHIV}_{89.6}$ (a chimeric virus consisting of the SIV gag-pol gene and HIV-1 env gene; (Lee et al., 2005), but did not inhibit SIV replication in the same host (Fig. 2A). This suggests that the anti-HIV-1 activity of DBM2198 might be associated with the HIV-1 envelope, rather than with the host receptor. To test this assumption, HIV-1-susceptible Magi cells were infected using three different infection protocols: (i) DBM-untreated cells were incubated with viruses that were pretreated with DBM-2198 for $1 \mathrm{~h}$; (ii) DBM-2198-treated cells were washed and infected with untreated viruses; or (iii) untreated cells were infected with treated viruses for $1 \mathrm{~h}$, and then cultured in the presence of $0.5 \mu \mathrm{M}$ DBM-2198. As shown by the visual infection assay (Fig. 4A) and its statistical data (Fig. 4B), viral infection was completely blocked by DBM-2198 when the viruses were pre-treated with DBM-2198 whereas infection of host cells with untreated viruses did not show such a dramatic inhibition regardless of DBM-2198 treatment of host cells before or after infection. These results indicate that DBM2198 blocked the viral attachment site rather than the host cell receptor. Both T-cell tropic (HIV-1 $1_{\text {IIIB }}$ and HIV-1cc) and monotropic (Ba-L) HIV-1 variants were similarly inactivated by DBM2198 pre-treatment (Fig. 4), suggesting that DBM-2198 might act on the HIV-1 general attachment site rather than the V3 region that plays a key role in the host tropism of each HIV-1 variant (T cell tropic or monotropic).

DBM-2198 interacts with HIV-1 gp120 without affecting the V3 region

COS-1 cells transfected with pcDNA-gp160 gave positive re-
Fig. 5. FACS analysis of DBM-2198 binding to HIV-1 envelope protein. (A) COS-1 cells were transfected with pcDNA-IIIBgp160 (COS-gp160) or pcDNA control vector (COS-1). After 2 days, gp160-expression was assessed by Western blotting (left) and FACS (right) analyses with antigp120 and anti-V3 antisera. (B) HIV-1 $1_{\text {IIB }}$ gp160expressing COS-1 cells were pre-treated with rabbit anti-gp120 (upper)/anti-V3 (lower) antisera or control rabbit serum, and then stained with 0.5 $\mu \mathrm{M}$ FITC-conjugated DBM-2198 for 30 min. After staining, the cells were analyzed on a FACSCalibur. Representative FACS data are shown. (B) Representative FACS data of HIV-1 $1_{\text {IIIB }}$ gp160expressing COS- 1 cells that were pre-treated with rabbit anti-V3(IIIB) antiserum and then stained and analyzed as above. (C) Cumulative results of three independent experiments of (B). Data show mean $\pm \mathrm{SD}$; ${ }^{\star \star} P<0.01$, indicating that anti-gp120mediated blocking was statistically significant. sults in both Western blot and FACS analysis with anti-gp120 and anti-V3 antibodies whereas COS-1 cells transfected with control vector yielded negative results (Fig. $5 \mathrm{~A}$ ), suggesting that gp160-transfected COS-1 cells express HIV-1 envelope on the cell surface. Upon FACS analysis, FITC-labeled DBM-2198 exhibited specific binding to the HIV-1 envelope expressed on the surface of COS-1 cells. This binding was significantly inhibited by pretreatment with anti-gp120 antisera (Fig. 5B, upper), but was not affected by pretreatment with anti-V3 antisera (Fig. $5 \mathrm{~B}$, lower). The results of these competitive inhibition assays were statistically significant (Fig. $5 \mathrm{C}$ ). These data imply that DBM-2198 acts on the viral attachment site on the HIV-1 gp120; however, in contrast to $\mathrm{P}=\mathrm{S}$ ONs, the anti-HIV-1 activity of AZPSON DBM-2198 is not associated with its binding to the $\mathrm{V} 3$ region of gp120.

\section{DISCUSSION}

Consistent with our previous reports (Lee et al., 2005), DBM2198 and some other AZPSONs proved to be potent inhibitors of HIV-1 replication by simple administration into HIV-1-infected cultures (Fig. 1A and Table 1). In the present study we have characterized the detailed mechanism underlying the anti-HIV-1 activity of DBM-2198 and other typical AZPSONs.

LTR-CAT-transformed cells (Figs. 1C and 1D) and Magi cells (Figs. 1E and 1F) were assessed with regard to LTR-mediated reporter expression upon simple treatment or transfection with DBM-2198 and other AZPSONs. Our results, shown in Fig. 1, indicate that the anti-HIV-1 activities of simple treatment with DBM-2198 and other AZPSONs were attributable to their 
extracellular mode of action, rather than to sequence-specific intracellular inhibitory mechanisms after membrane transduction.

Our finding that the anti-HIV-1 activity of AZPSONs was attributable to an extracellular mode of action led us to question whether these molecules block cell surface molecules and result in inhibition of other viral infections. However, the replication of poliovirus or SIV was not inhibited by the presence of AZPSONs at concentrations required for the sterile inhibition of HIV-1 replication (Fig. 2). This indicated that the anti-HIV-1 activity exhibited by the AZPSONs is highly specific to HIV-1. Moreover, intracellular $\mathrm{Ca}^{2+}$ influx was not observed in cells treated with the AZPSON DBM-2198, whereas $\mathrm{Ca}^{2+}$ elevation was clearly observed in the DBM-2136-treated cells (Fig. 3A), implying that DBM-2198 treatment does not affect the cell surface molecules involved in cell signaling or activation. This result suggests that DBM-2198 treatment may not cause any undesirable side effects through nonspecific activation of naive cells in vivo.

In the present study, SIV proved to be resistant to DBM-2198 (Fig. 2A), whereas $\mathrm{SHIV}_{89.6}$ (a chimeric virus consisting of the SIV-originated gag-pol gene and the HIV-1-derived env gene) was very sensitive, as demonstrated in our previous report (Lee et al., 2005). These results imply that the anti-HIV-1 activity of DBM-2198 is associated with the HIV-1 envelope. This assumption was further verified by a series of infection experiments (Fig. 4), and by direct FACS analysis (Fig. 5). Among the three different infection protocols, infections were completely blocked only when HIV-1 was pre-treated with DBM-2198 before infection, and this phenomenon was similarly repeated in three independent trials with 3 different HIV-1 variants, regardless of their host tropisms (Fig. 4). FACS analysis of gp160expressing COS-1 cells with FITC-labeled DBM-2198 revealed that DBM-2198 has a specific affinity for the HIV-1 envelope protein, and that this affinity was inhibited by anti-gp120 antiserum (Figs. 5B and $5 \mathrm{C}$ ). Several polyanionic $\mathrm{P}=\mathrm{S}$ ONs were implicated in direct binding to the V3 loop of HIV-1 gp120 (Buckheit et al., 1994; Stein et al., 1993; Suzuki et al., 1999; Wyatt et al., 1994). However, we could not detect any inhibition of DBM-2198 binding to gp160 by anti-V3 antiserum in the FACS competition assay (Figs. $5 \mathrm{~B}$ and $5 \mathrm{C}$ ) indicating that the V3 domain of HIV-1 was not involved in the antiviral activity of DBM-2198. In our previous report (Lee et al., 2005), DBM-2198 was demonstrated to inhibit both T-cell tropic (IIIB and cc) and monotropic (Ba-L) viruses, implying that the tropism-related V3 region may not be a target for DBM-2198-mediated blocking of HIV-1. Nevertheless, we are unable to completely dismiss the possibility that DBM-2198 binds to the V3 domain on the basis of our present results because the V3 region is not exposed in the normal conformation of gp120 (Bou-Habib et al., 1994; Pinter et al., 1993).

In conclusion, DBM-2198 and some other AZPSONs inhibit HIV-1 infection and spreading via blockage of the viral attachment site on HIV-1 gp120, without affecting the condition of the host cells. Our findings provide a better understanding of the antiviral mechanism of DBM2198 and other AZPSONs, and may contribute to further study of DBM-2198 for the development of a potential therapeutic drug against a broad spectrum of HIV-1 variants.

\section{ACKNOWLEDGMENTS}

We thank Dr. J. Sodroski for the HXBc2, HXBc2/Atat, pSV2-tat plasmids and the Jurkat-tat strain, and Drs. A. Nomoto and E. Wimmer for the poliovirus cDNA. We are grateful to D.S. Lee and C. H. Yoon for their enthusiastic support of this work. This work was supported in part by a Research Fellow Grant of SEB (NRF-2013R1A1A2064954) and by the Bio \& Medical Technology Development Program (2012M3A9B402826) of the Korea National Research Foundation (NRF) funded by the Korean Ministry of Education Science and Technology.

\section{REFERENCES}

Asoh, S., Ohsawa, I., Mori, T., Katsura, K., Hiraide, T., Katayama, Y., Kimura, M., Ozaki, D., Yamagata, K., and Ohta, S. (2002). Protection against ischemic brain injury by protein therapeutics. Proc. Natl. Acad. Sci. USA 99, 17107-17112.

Bou-Habib, D.C., Roderiquez, G., Oravecz, T., Berman, P.W., Lusso, P., and Norcross, M.A. (1994). Cryptic nature of envelope V3 region epitopes protects primary monocytotropic human immunodeficiency virus type 1 from antibody neutralization. J. Virol. 68, 6006-6013.

Buckheit, R.W., Jr., Roberson, J.L., Lackman-Smith, C., Wyatt, J.R., Vickers, T.A., and Ecker, D.J. (1994). Potent and specific inhibition of HIV envelope-mediated cell fusion and virus binding by $\mathrm{G}$ quartet-forming oligonucleotide (ISIS 5320). AIDS Res. Hum. Retroviruses 10, 1497-1506.

Feske, S. (2013). $\mathrm{Ca}(2+)$ influx in T cells: how many $\mathrm{ca}(2+)$ channels? Front. Immunol. 4, 99.

Fraietta, J.A., Mueller, Y.M., Do, D.H., Holmes, V.M., Howett, M.K., Lewis, M.G., Boesteanu, A.C., Alkan, S.S., and Katsikis, P.D. (2010). Phosphorothioate 2' deoxyribose oligomers as microbicides that inhibit human immunodeficiency virus type 1 (HIV-1) infection and block Toll-like receptor 7 (TLR7) and TLR9 triggering by HIV-1. Antimicrob. Agents Chemother. 54, 40644073.

Gebert, L.F., Rebhan, M.A., Crivelli, S.E., Denzler, R., Stoffel, M., and Hall, J. (2014). Miravirsen (SPC3649) can inhibit the biogenesis of miR-122. Nucleic Acids Res. 42, 609-621.

Giannecchini, S., Clausi, V., Nosi, D., and Azzi, A. (2009). Oligonucleotides derived from the packaging signal at the $5^{\prime}$ end of the viral PB2 segment specifically inhibit influenza virus in vitro. Arch. Virol. 154, 821-832.

Gonzalez-Carmona, M.A., Quasdorff, M., Vogt, A., Tamke, A., Yildiz, Y., Hoffmann, P., Lehmann, T., Bartenschlager, R. Engels, J.W., Kullak-Ublick, G.A., et al. (2013). Inhibition of hepatitis $C$ virus RNA translation by antisense bile acid conjugated phosphorothioate modified oligodeoxynucleotides (ODN). Antiviral Res. 97, 49-59.

Jing, N., and Hogan, M.E. (1998). Structure-activity of tetradforming oligonucleotides as a potent anti-HIV therapeutic drug. J. Biol. Chem. 273, 34992-34999.

Jing, N., Marchand, C., Liu, J., Mitra, R., Hogan, M.E., and Pommier, Y. (2000). Mechanism of inhibition of HIV-1 integrase by G-tetrad-forming oligonucleotides in vitro. J. Biol. Chem. 275, $21460-21467$.

Jung, K.E., Kim, K., Yang, M., Lee, K., and Lim, H. (1999). Synthesis and hybridization properties of oligonucleotides containing 6-membered azasugar nucleotides. Bioorg. Med. Chem. Lett. 9, 3407-3410.

Khan, M.A., Chen, H.C., Wan, X.X., Tania, M., Xu, A.H., Chen, F.Z., and Zhang, D.Z. (2013). Regulatory effects of resveratrol on antioxidant enzymes: a mechanism of growth inhibition and apoptosis induction in cancer cells. Mol. Cells 35, 219-225.

Kimpton, J., and Emerman, M. (1992). Detection of replicationcompetent and pseudotyped human immunodeficiency virus with a sensitive cell line on the basis of activation of an integrated beta-galactosidase gene. J. Virol. 66, 2232-2239.

Koning, F.A., Otto, S.A., Hazenberg, M.D., Dekker, L., Prins, M., Miedema, F., and Schuitemaker, H. (2005). Low-level CD4+ T cell activation is associated with low susceptibility to HIV-1 infection. J. Immunol. 175, 6117-6122.

Lanford, R.E., Hildebrandt-Eriksen, E.S., Petri, A., Persson, R., Lindow, M., Munk, M.E., Kauppinen, S., and Orum, H. (2010). Therapeutic silencing of microRNA-122 in primates with chronic hepatitis $C$ virus infection. Science $327,198-201$.

Lee, D.S., Jung, K.E., Yoon, C.H., Lim, H., and Bae, Y.S. (2005). Newly designed six-membered azasugar nucleotide-containing 
phosphorothioate oligonucleotides as potent human immunodeficiency virus type 1 inhibitors. Antimicrob. Agents Chemother. 49, 4110-4120.

Luganini, A., Caposio, P., Landolfo, S., and Gribaudo, G. (2008). Phosphorothioate-modified oligodeoxynucleotides inhibit human cytomegalovirus replication by blocking virus entry. Antimicrob. Agents Chemother. 52, 1111-1120.

Marshall, W.S., and Caruthers, M.H. (1993). Phosphorodithioate DNA as a potential therapeutic drug. Science 259, 1564-1570.

Marshall, W.S., Beaton, G., Stein, C.A., Matsukura, M., and Caruthers, M.H. (1992). Inhibition of human immunodeficiency virus activity by phosphorodithioate oligodeoxycytidine. Proc. Natl. Acad. Sci. USA 89, 6265-6269.

Matsumura, T., Hu, Z., Kato, T., Dreux, M., Zhang, Y.Y., Imamura, M., Hiraga, N., Juteau, J.M., Cosset, F.L., Chayama, K., et al. (2009). Amphipathic DNA polymers inhibit hepatitis $C$ virus infection by blocking viral entry. Gastroenterology 137, 673-681.

Miah, M.A., Byeon, S.E., Ahmed, M.S., Yoon, C.H., Ha, S.J., and Bae, Y.S. (2013). Egr2 induced during DC development acts as an intrinsic negative regulator of DC immunogenicity. Eur. J. Immunol. 43, 2484-2496.

Pinter, A., Honnen, W.J., and Tilley, S.A. (1993). Conformational changes affecting the V3 and CD4-binding domains of human immunodeficiency virus type 1 gp120 associated with env processing and with binding of ligands to these sites. J. Virol. 67, 5692-5697.

Stein, C.A., Cleary, A.M., Yakubov, L., and Lederman, S. (1993). Phosphorothioate oligodeoxynucleotides bind to the third variable loop domain (v3) of human immunodeficiency virus type $1 \mathrm{gp} 120$. Antisense Res. Dev. 3, 19-31.

Suzuki, J., Miyano-Kurosaki, N., Takeuchi, H., Tamura, Y., Kawai, G., Takai, K. Tanaka, Y., Tanaka, R., Yamamoto, N., and Takaku, H. (1999). Phosphorothioate G3T4G3 motifs inhibits the early stage of HIV-1 infection. Nucleic Acids Symp. Ser. 42, 227228.
Takahashi, T., Ohzawa, T., Sawada, S., Kato, N., Goto, N., Nakamura, S., Yasunaga, T., and Kaihatsu, K. (2009). Inhibition of influenza virus infection by targeting genome conserved region with non-natural nucleic acid. Nucleic Acids Symp. Ser. (Oxf). 53, 285-286.

Torrence, P.F., Gupta, N., Whitney, C., and Morrey, J.D. (2006). Evaluation of synthetic oligonucleotides as inhibitors of West Nile virus replication. Antiviral Res. 70,60-65.

Vaillant, A., Juteau, J.M., Lu, H., Liu, S., Lackman-Smith, C., Ptak, R., and Jiang, S. (2006). Phosphorothioate oligonucleotides inhibit human immunodeficiency virus type 1 fusion by blocking gp41 core formation. Antimicrob. Agents Chemother. 50, 13931401.

Velazquez-Campoy, A., Todd, M.J., Vega, S., and Freire, E. (2001). Catalytic efficiency and vitality of HIV-1 proteases from African viral subtypes. Proc. Natl. Acad. Sci. USA 98, 6062-6067.

Vodicka, M.A., Goh, W.C., Wu, L.I., Rogel, M.E., Bartz, S.R., Schweickart, V.L., Raport, C.J., and Emerman, M. (1997) Indicator cell lines for detection of primary strains of human and simian immunodeficiency viruses. Virology 233, 193-198.

Wulfing, C., Sjaastad, M.D., and Davis, M.M. (1998). Visualizing the dynamics of $\mathrm{T}$ cell activation: intracellular adhesion molecule 1 migrates rapidly to the $\mathrm{T}$ cell/B cell interface and acts to sustain calcium levels. Proc. Natl. Acad. Sci. USA 95, 6302-6307.

Wyatt, J.R., Vickers, T.A., Roberson, J.L., Buckheit, R.W., Jr., Klimkait, T., DeBaets, E., Davis, P.W., Rayner, B., Imbach, J.L., and Ecker, D.J. (1994). Combinatorially selected guanosinequartet structure is a potent inhibitor of human immunodeficiency virus envelope-mediated cell fusion. Proc. Natl. Acad. Sci. USA 91, 1356-1360.

Yoon, C.H., Lee, E.S., Lim, D.S., and Bae, Y.S. (2009). PKR, a p53 target gene, plays a crucial role in the tumor-suppressor function of p53. Proc. Natl. Acad. Sci. USA 106, 7852-7857.

Zack, J.A., Kim, S.G., and Vatakis, D.N. (2013). HIV restriction in quiescent CD4(+) T cells. Retrovirology 10, 37. 